\title{
Application of The Robotic Seal PARO, A Neurological Biofeedback Medical Device, to Elderly Persons with Dementia at Home: An Analysis From Seven Cases
}

Kaoru Inoue ( $\square$ inoue@tmu.ac.jp )

Graduate School of Human Health Sciences, Tokyo Metropolitan University

Chiyomi Yatsu

Fraser Health

Daryl Patrick Yao

Graduate School of Human Health Sciences, Tokyo Metropolitan University

Chihiro Sasaki

Nursing Station Hanakirin

Kazuyoshi Wada

Graduate School of Systems Design, Tokyo Metropolitan University

Takanori Shibata

National Institute of Advanced Industrial Science and Technology

\section{Research Article}

Keywords: Dementia Care, Home Care, Family Caregiver, User Acceptance, Seal Robot, Person-Centred Care, Occupational Therapy, Japan

Posted Date: January 14th, 2021

DOI: https://doi.org/10.21203/rs.3.rs-137560/v1

License: (c) (i) This work is licensed under a Creative Commons Attribution 4.0 International License. Read Full License 
2 Device, to Elderly Persons with Dementia at Home: An Analysis from Seven Cases

3 Kaoru Inoue $^{1}$, Chiyomi Yatsu $^{2}$, Daryl Patrick G. Yao ${ }^{1}$, Chihiro Sasaki $^{3}$, Kazuyoshi Wada $^{4}$,

4 Takanori Shibata ${ }^{5}$

5

61 Graduate School of Human Health Sciences, Tokyo Metropolitan University, 7-2-10

7 Higashiogu, Arakawa-ku, Tokoyo, 116-8551, Japan.

82 Fraser Health, Suite 400, Central City Tower, 13450 - 102nd Avenue, Surrey, BC

$9 \quad$ V3T 0H1, Canada

103 Nursing Station Hanakirin, 7-2-5-102, Higashikasai, Edogawa-ku, Tokyo, 134-0084,

11 Japan.

124 Graduate School of Systems Design, Tokyo Metropolitan University, 6-6,

13 Asahigaoka, Hino city, Tokyo, 191-0065, Japan.

145 Human Informatics and Interaction Research Institute, National Institute of

15 Advanced Industrial Science and Technology (AIST), 1-1-1 Umezono, Tsukuba,

16 Ibaraki 305-8568, Japan

17

18 Corresponding author: Kaoru Inoue (inoue@tmu.ac.jp) 


\section{ABSTRACT}

Background: In Japanese society today, many elderly persons with dementia (EPWD) are living at home. This research focused on the family members of EPWD who provide informal care and support. The purpose of this research was (1) to analyse the potential and effectiveness of care provided by the family with the use of the robotic seal PARO, a neurological biofeedback medical device, and (2) to identify and prioritise problems when utilising PARO in the home context.

Methods: This study employed a mixed-methods approach involving observational data and interviews. Family members of seven households caring for EPWD were asked to use the seal robot "PARO" as a means to provide care. The family caregivers used PARO at home for more than three times per week, over one to three months. At the initial visit, an individualised purpose of PARO was established. Family members were taught how to operate PARO and how to facilitate PARO use. Research data were collected at initial and subsequent monthly visits, in the form of families' observational feedback, interviews, and direct assessment of the subjects. Collected data were analysed quantitatively and qualitatively. 
37 Results: Five out of the seven elderly persons reacted positively to PARO and achieved their intervention goals. Acceptance of PARO use depended on the positive interaction observed at the initial encounter, which led to continued interest later on. On the other hand, for the subjects where "encouragement was required to trigger interaction" at the initial encounter, their subsequent interest may either increase or decrease. Furthermore, observed activities with PARO use for all families were conversations and physical touch to PARO. Some families facilitated reminiscence and intellectual activities.

Conclusions: The study indicated that the effect of PARO application at home is possibly influenced by the participants' initial level of interest towards PARO. It is still crucial to perform careful observation and assessment of the benefit of PARO before adapting the treatment strategy. The families need specific advice from relevant healthcare professionals, such as occupational therapists, to maximise the use of PARO. This implies that effective robotic care at home requires professional support.

Keywords: Dementia Care, Home Care, Family Caregiver, User Acceptance, Seal Robot, 


\section{BACKGROUND}

Many of the Japanese elderly wish to live the rest of their lives in environments familiar to them, even if they may become heavily in need of long-term care. The Japanese Ministry of Health, Labour and Welfare (MHLW) established a scheme called 'the Community-based Integrated Care System' to ensure adequate provision of health care, nursing care, prevention, housing, and livelihood support [1].

61 According to Chiao's systematic review regarding the burden on families of elderly persons with dementia (EPWD), numerous studies highlighted the importance of educating families [2]. In Japan, the burden of care carried by families who care for EPWD has become a major problem. In 2006 the Act on the Prevention of Abuse against the Elderly and the Support of Elderly Caregivers, which focuses on the protection of human rights for the elderly, came into force [3]. Since this law's enforcement, the Japanese government has been collecting data related to elderly abuse. In a nationwide survey in 2018, caregivers' fatigue and stress were the number one causes of domestic abuse. The Japanese government, organisations in support of persons with dementia, and researchers have asserted the necessity to reduce the burden of giving care, provide psychological support, and educate family caregivers for families living with EPWD. A 
73 health care provider (HCP) historically played a leading role in this context. However,

74 considering steady increase in the number of reported abuse from 273 cases in 2006 to

751723 cases in 2016, including abuses committed by family members to EPWD, it shows

76 that the current system alone cannot easily solve the problem.

78 The support provision as stipulated within the social policy is reasonable. However, it is necessary to review the contents and process of support. It is important to educate family members the knowledge to care for EPWD. However, without a specialised background,

81 it is a challenge for a layperson to understand theories and practices meant for HCP.

82 Therefore, easily understandable care methods that everyone can practice are essential.

The emergence of an ageing society led to an increased number of EPWD. As of 2017, Japan had reached the world's highest number of elderly people, necessitating the need

86 for a strategy to address dementia and its symptoms [4]. According to the MHLW, 87 healthcare staff required for fiscal 2025 are approximately 2.45 million people, with an expected shortage of about 0.34 million. Thus, providing adequate long-term care services may become a challenge [5]. "Hands-on care" alone may not be adequate to meet the demand, hence adapting "care by device" can be a viable strategy to compensate for 
the labour shortage.

93 The Government of Japan promotes the development and practical use of robots under

94 the "new robot strategy" [6]. Moreover, the use of robots in the medical and nursing field

95 is flourishing, becoming one of the major industries in Japan. While there exist numerous

96 clinical trials on medical robots, most of them, especially those using a Randomised

97 Controlled Trial (RCT) design, have focused on the Japanese-made baby seal robot "PARO", a neurological therapeutic medical device certified by the United States Food and Drug Administration [7]. At present, PARO is used in the medical and welfare fields in various developed countries and regions such as the United States, Canada, Europe, Asia, and Oceania. According to Kang's systematic review, PARO is effective in improving QOL, emotions, social interaction, and reducing the amount of medication for neuropsychiatric symptoms [8]. In Hung's scoping review, reducing negative feelings and problematic behaviour as well as improving social interaction and eagerness of caregiver are the benefits of using PARO [9]. Several studies found that the use of PARO among EPWDs could impact different aspects of the EPWD such as improved quality of life and enjoyment, facial expression 
and communication, mood, and diminished stress, anxiety, and use of antipsychotic

110 medication, and neutral affect [10-15]. Additionally, PARO can positively influence the

111 physical activation of EPWDs without altering their sleep patterns [16]. Thus, several

112 studies recommended PARO for people with mild to moderate agitation brought about by

113 dementia and community-dwelling seniors who attend day-care programs $[13,17]$.

115 Despite the numerous studies, most of these were obtained from healthcare facilities

116 administered by trained HCPs. Furthermore, the only research conducted within one's

117 natural environment did not look into the effects of using PARO solely at home as it was

118 a combination of daytime PARO use in a day-care centre and home [13]. Families of

119 EPWD are already using everyday technology such as alarmed sensors and internets but

120 the everyday use of robots are not as common $[18,19]$. Thus, it is of benefit to consider

121 PARO use, as the use of robots has the potential to contribute greatly to the extension of community living and become one of the solutions to providing high-quality home care.

124 To use a neurological biofeedback medical robot at home, the family must be able to operate it easily and effectively. Adapting the Person-Centred Care (PCC) approach to improve the quality of care is a possible approach for both family members and HCPs as 
127 the theory is not exclusive to the experts. PCC is a theory of dementia care proposed by

128 British social psychologist Tom Kidwood. He believes that personhood can be maintained

129 by meeting five needs namely: Comfort, Identity, Attachment, Occupation, and Inclusion

130 [20]. From the result of the abovementioned studies, introducing robots to family care can

131 potentially meet the five needs of PCC by engaging with the subjects. Furthermore, it is

132 possible to demonstrate the difference between good care and not so good care from

133 realistic examples while considering the individual circumstances of the family.

134 EPWDs often find it difficult to accurately convey their feelings to others, therefore it is

135 crucial for the caregiver to objectively observe the person to determine the condition when

136 providing care. EPWDs also present with reduced judgement skill to make every-day life

137 decisions, therefore, to ethically provide care by a robot, the viewpoint of the EPWD must

138 be considered. PCC is an approach to dementia care that can be applied in two

139 perspectives: as a way of supporting families and as an education method.

141 This study aimed to examine the possibilities of care by the family using the neurological

142 biofeedback medical robot, PARO. The purpose of this research was (1) to analyse the

143 potential and effectiveness of care provided by the family with the use of PARO, and (2)

144 to identify and prioritise problems when utilising PARO in the home context. 


\section{METHODS}

147 Design:

148 A mixed-methods approach involving standardised assessments, observational data, and

149 interviews with a family member of an EPWD was employed to investigate the

150 possibilities of utilising robots as part of home care.

$\underline{\text { Tools and Materials: }}$

153 In this research, a neurological biofeedback medical robot called "PARO" (Intelligent

154 Systems Inc.) was used (Fig. 1). PARO is a baby seal shaped robot (9th generation, about

$15557 \mathrm{~cm}$, about $2.5 \mathrm{~kg}$ ) developed at the National Institute of Advanced Industrial Science

156 and Technology (Japan).

158 Guided by the notions behind animal-assisted therapy, a therapy robot PARO was developed to facilitate the users' psychological, physical and social wellbeing [21].

160 PARO's functions are described as following: PARO does not speak a language or walk,

161 but it is capable of making an animal-like cry, moves its head and legs, and blinks. With

162 excellent artificial intelligence, it has a learning function such as remembering the name 
163 of a person and endears itself to its owner with cute gestures and cries. Also, high safety

164 standards through antibacterial processed fur and magnetic shielding function enable

165 PARO to be used in intensive care settings [22].

166

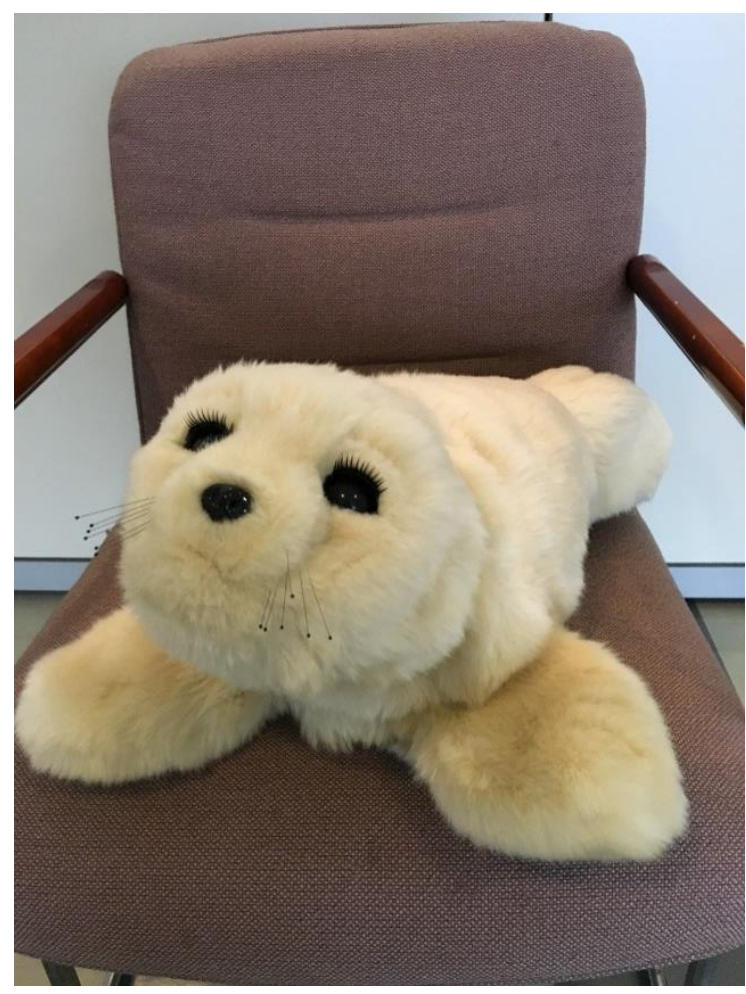

Figure 1: PARO

\section{$\underline{\text { Participants: }}$}

171 The participants of this research are home-dwelling EPWD who live with and receive

172 care from their families. The inclusion criteria were set as elderly (over age 65)

173 individuals diagnosed with dementia, with no severe consciousness disorder, residing at 
174 home with a family member, and who, by assessment of a qualified HCP, is expected to

175 benefit from using PARO. Other criteria such as the severity of cognitive deficits were

176 not set.

177

178 Recruitment:

179 The research team distributed a recruitment brochure that stipulated an overview of the

180 research amongst dementia support groups in the Tokyo metropolitan area and Long-

181 Term Care Insurance case managers' gatherings. Interested volunteer participants

182 contacted the principal researcher to schedule an initial home visit. Both the principal

183 investigator (PI) and the case HCP conducted the initial home visit. The PI explained the

184 content of research as well as the known effectiveness of PARO before obtaining the

185 participants' agreement. Once the participant agreed, PARO was presented to the research

186 subject to examine for any negative reaction. Negative reactions such as anxious

187 expression, sad expression, disturbing behaviour, and anger towards PARO were

188 perceived as an indication of their refusal to participate. These individuals were then

189 excluded from further participation. informed consent was obtained from participants and

190 family.

191 
193 Once the research subject's participation in the trial was ascertained, the PI, the case HCP,

194 and their family collaboratively established a goal for using PARO in light of the 195 previously explained effectiveness of PARO $[10,12,13]$. Then, the PI and the case HCP

196 completed standardised assessments for the subjects and collected information from the

197 family including the subject's sex, diagnosis, level of required care, and history of

198 experience with pets. At the end of the initial visit, the PI advised the family regarding

199 the set-up, operation, maintenance, and timing of use of PARO. The following

200 recommendations were given:

201 (1) PARO is placed on a spot easily seen by the subject,

(2) provide verbal and gestural prompts to encourage interaction with PARO, and

(3) allocate time to communicate with the subject about PARO among other topics.

The family was encouraged to contact the PI at any time for consultation. The family then

proceeded to present PARO to the subject at least three times per week for one month. At every month interval, the case HCP conducted home visits to monitor the subjects through observation and interviews with family caregivers regarding the subject's general condition, numbers and ways of encounter with PARO, and the subject's reaction to

PARO. At the final visit, in addition to the above-mentioned monthly procedures, the case 
210 HCP repeated the standardised assessments and conducted a semi-structured informal

211 interview regarding PARO use. Key questions for jumpstarting the conversation are

212 found in Supplement 1. The family's comments were recorded through an audio recorder,

213 which was later transcribed. The process of data collection was synthesised as shown in

214 Figure 2.

215

216

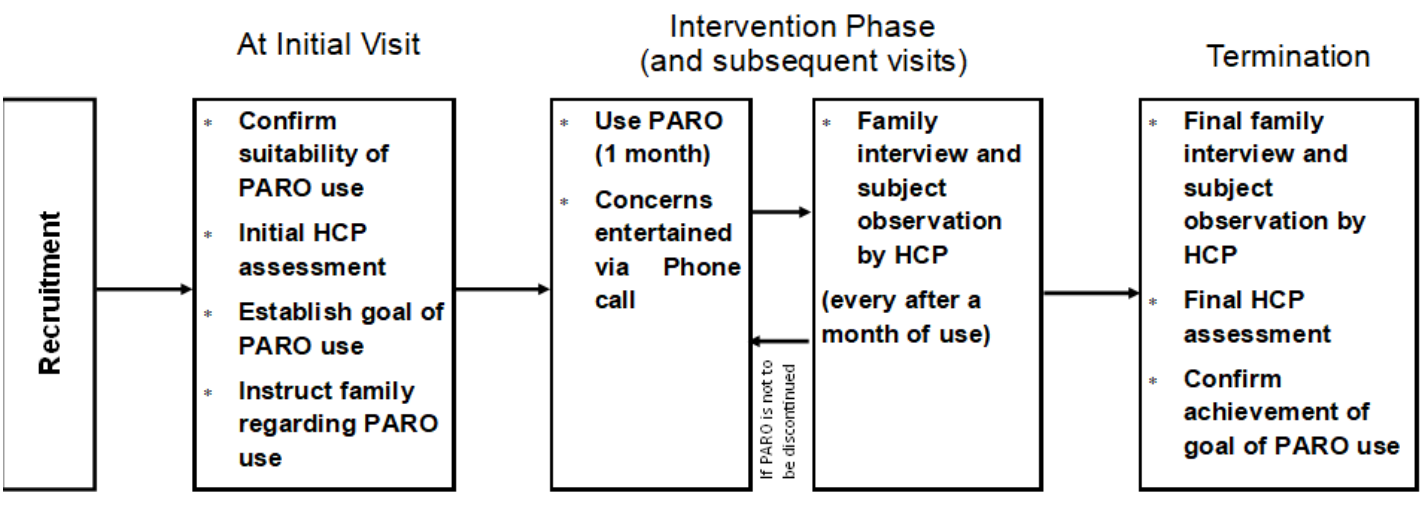

Figure 2 Process of data collection

219 Outcome measures and methods of analysis

220 Standardised assessment:

221 A series of standardised assessments were conducted at the start and the end of PARO

222 intervention. The assessments included: Mini-Mental Status Examination-Japanese

223 (MMSE-J), Nishimura's Activity of Daily Living Scale (N-ADL), Dementia Behaviour

224 Disturbance (DBD) Scale, and Zarit Burden Interview [23-26]. The MMSE-J is an official 
225 Japanese edition of the Mini-Mental State Examination, a screening test for detecting

226 dementia wherein a grade lower than 23/30 may indicate dementia [27]. The N-ADL is a

227 simple Japanese test that evaluates the level of ADL independence by observing the

228 behaviour of an elderly person with suspected dementia wherein a full score of 50

229 indicates normal [24]. The DBD Scale by Baumgarten is a 28-items, 5-point scale

230 totalling 112 points used to observe the behaviour of people with dementia [25]. In this

231 study, the Japanese version of DBD was used [28]. Lastly, the Zarit Burden Interview is

232 an assessment tool that objectively evaluates the feeling of burden experienced by

233 caregivers of people with dementia and other conditions requiring assistance [26]. In this

234 research, we used the Japanese version standardised by Arai [29].

Interview with family caregiver:

237 An inductive analysis method was employed to categorise collected qualitative data.

238 First, the PI transcribed the family caregivers' comments recorded in the IC recorder, then

239 selected key sentences or keywords rephrased into short sentences (codes). These codes

240 were synthesised into sub-categories, then into categories. Three experienced HCPs

241 collectively reviewed these codes and categories to clarify any uncertainty. The PI revised

242 short sentences until a unanimous agreement was reached. 


\section{Observation:}

245 The subject's behaviours, which include (1) state of interactions with PARO and (2)

246 changes in interest towards PARO, were observed and documented by the case HCPs

247 during monthly visits. This was supplemented by reports extracted from the interviews

248 with the family caregivers. The resulting data were analysed qualitatively for all cases to

249 identify similarities and differences.

250 (1) The subjects' behaviour: To categorise the behaviour of the subjects, the

of DCM [31]. Examples of the BCC are:

- A (Articulation): Interaction with others verbally or otherwise,

- $\mathrm{G}$ (Going back): Reminiscence and life review,

- I (Intellectual): The use of intellectual abilities and

- $\mathrm{O}$ (Objects): Displaying attachment to or relating to inanimate objects [31].

The definition of PCC was considered for determining whether a subject's responses were positive or negative. 

was graded using timeline graphs. A five-level grading scale was used to

\section{RESULTS}

274 The subjects' profile and the result of standardised assessments are shown in Table 1.

275 Out of ten families who volunteered to participate, seven families were included in this

276 research. Subjects were 6 female and 1 male. Family caregivers include 4 sons, 2

277 daughters, and 1 daughter-in-law. 
279 At the beginning of the research, the MMSE score ranged from 4 to 21 points, the N-ADL

280 score from 2 to 46 points, the DBD from 12 to 40 points, and the Zarit care burden score

281 from 14 to 40 points. Throughout the data collection period, none of the subjects was

282 diagnosed with any new medical conditions, nor was their existing medicines changed. 


\section{Table 1: Participants' profile and the result of standardised assessments}

\begin{tabular}{|c|c|c|c|c|c|c|c|c|c|c|c|c|c|c|}
\hline & \multicolumn{2}{|c|}{ Case 1} & \multicolumn{2}{|c|}{ Case 2} & \multicolumn{2}{|c|}{ Case 3} & \multicolumn{2}{|c|}{ Case 4} & \multicolumn{2}{|c|}{ Case 5} & \multicolumn{2}{|c|}{ Case 6} & \multicolumn{2}{|c|}{ Case 7} \\
\hline Age/Sex & \multicolumn{2}{|c|}{$86 / \mathrm{F}$} & \multicolumn{2}{|c|}{$82 / \mathrm{F}$} & \multicolumn{2}{|c|}{$97 / \mathrm{F}$} & \multicolumn{2}{|c|}{$79 / \mathrm{F}$} & \multicolumn{2}{|c|}{ 97/M } & \multicolumn{2}{|c|}{$85 / F$} & \multicolumn{2}{|c|}{$85 / F$} \\
\hline $\begin{array}{c}\text { Diagnosis } \\
\text { \& Care level* }\end{array}$ & \multicolumn{2}{|c|}{$\begin{array}{c}\text { Alzheimer's } \\
\text { Dementia } \\
\text { (level 1) }\end{array}$} & \multicolumn{2}{|c|}{$\begin{array}{c}\text { Alzheimer's } \\
\text { Dementia } \\
\text { (level 1) }\end{array}$} & \multicolumn{2}{|c|}{$\begin{array}{c}\text { Alzheimer's } \\
\text { Dementia } \\
\text { (level 4) }\end{array}$} & \multicolumn{2}{|c|}{$\begin{array}{c}\text { Alzheimer's } \\
\text { Dementia } \\
\text { (level 3) }\end{array}$} & \multicolumn{2}{|c|}{$\begin{array}{c}\text { Alzheimer's } \\
\text { Dementia } \\
\text { (level 4) }\end{array}$} & \multicolumn{2}{|c|}{$\begin{array}{l}\text { Dementia } \\
\text { (level 4) }\end{array}$} & \multicolumn{2}{|c|}{$\begin{array}{c}\text { Alzheimer's } \\
\text { Dementia } \\
\text { (level 1) }\end{array}$} \\
\hline $\begin{array}{c}\text { Experience with } \\
\text { pets }\end{array}$ & \multicolumn{2}{|c|}{ Had a dog } & \multicolumn{2}{|c|}{$\begin{array}{c}\text { Had a dog and } \\
\text { cat }\end{array}$} & \multicolumn{2}{|c|}{ Had a dog } & \multicolumn{2}{|c|}{$\begin{array}{l}\text { Had a dog, cat, } \\
\text { \& bird }\end{array}$} & \multicolumn{2}{|c|}{$\begin{array}{c}\text { Had various } \\
\text { pets }\end{array}$} & \multicolumn{2}{|c|}{ Likes animals } & \multicolumn{2}{|c|}{$\begin{array}{l}\text { Had a pet (but } \\
\text { dislikes animal) }\end{array}$} \\
\hline Caregiver & \multicolumn{2}{|c|}{$\begin{array}{c}\text { Daughter-in- } \\
\text { law }\end{array}$} & \multicolumn{2}{|c|}{ Eldest daughter } & \multicolumn{2}{|c|}{ Eldest son } & \multicolumn{2}{|c|}{$\begin{array}{c}\text { Eldest } \\
\text { Daughter }\end{array}$} & \multicolumn{2}{|c|}{ Eldest son } & \multicolumn{2}{|c|}{$\begin{array}{c}\text { Husband \& } \\
\text { eldest son } \\
\text { (lives nearby) }\end{array}$} & \multicolumn{2}{|c|}{ Eldest son } \\
\hline \multirow[t]{2}{*}{ Caregiver's age } & & & & & & & & & & & & & & \\
\hline & Pre & Post & Pre & Post & Pre & Post & Pre & Post & Pre & Post & Pre & Post & Pre & Post \\
\hline MMSE-J & 16 & 17 & 21 & NT & 4 & 10 & 13 & 5 & 15 & 19 & 5 & NT & 14 & 14 \\
\hline N-ADL & 42 & 36 & 46 & NT & 2 & 15 & 41 & 40 & 14 & 14 & 25 & 27 & 25 & 31 \\
\hline DBD & 23 & 23 & 17 & NT & 12 & 20 & 35 & 35 & 19 & 14 & 12 & 11 & 40 & 18 \\
\hline Zarit & 14 & 13 & 29 & NT & 27 & 28 & 40 & 35 & 33 & 30 & 12 & 7 & 33 & 12 \\
\hline
\end{tabular}


286 The purpose of introducing PARO to the participants included: to increase spontaneous

287 activity (5 cases), to reduce uneasiness/restlessness (4 cases), to feel uplifted (3 cases), to

288 feel soothed ( 2 cases), and to reduce family's burden of supervision ( 2 cases). An

289 overview of the subjects' goal achievement is shown in Table 2. The cases who achieved

290 their goal demonstrated interest and curiosity toward PARO from the initial encounter

291 through displaying the following common behaviours: (1) looking at PARO with

292 enthusiasm and (2) leaning forward to touch PARO with or without encouragement from

293 others. These individuals were noted to interact with PARO voluntarily, smiled more, and

294 communicated with their families more.

296 In observing the subjects' interaction with PARO, (A) verbal communication and (O)

297 relating to PARO were common to all cases. Additionally, during the interview, family

298 caregivers of two cases (case 1,3) reported that the use of PARO reminded the subject of

299 their experience in caring for a child or their pet $(\mathrm{G})$. The caregiver of case 3 also reported

300 that the subject showed an increased level of curiosity by asking questions (I), such as

301 "where do seals live".

303 Regarding the change in the level of interest towards PARO, cases that achieved their 
304 goal either maintained a high level of interest or demonstrated a positive shift of interest.

305 These subjects tend to talk with PARO, touch voluntarily or with minimal encouragement,

306 lean towards PARO, and gaze at PARO with a smile and a relaxed facial expression.

307 Individuals who demonstrated positive traits behaved as if caring for a child, talked about

308 PARO with family and acquaintances, requested to see PARO, gazed at PARO with a 309 smile, and petted PARO.

310

311 Discontinuation of the use of PARO was on the first month for two families, the second

312 month for another two families, and on the third month for three families. Reasons for

313 discontinuation were poor physical condition of the subject (4 cases), loss of interest in

314 PARO (2 cases), and the family becoming too busy (1 case). 


\begin{tabular}{|c|c|c|c|c|c|c|c|}
\hline & Case 1 & Case 2 & Case 3 & Case 4 & Case 5 & Case 6 & Case 7 \\
\hline $\begin{array}{c}\text { Goal } \\
\text { achievement }\end{array}$ & Not achieved & Achieved & Achieved & Not Achieved & Achieved & Achieved & Achieved \\
\hline BCC & $\mathrm{A}, \mathrm{G}, \mathrm{O}$ & $\mathrm{A}, \mathrm{O}$ & $\mathrm{A}, \mathrm{G}, \mathrm{I}, \mathrm{O}$ & $\mathrm{A}, \mathrm{O}$ & $\mathrm{A}, \mathrm{O}$ & $\mathrm{A}, \mathrm{O}$ & $\mathrm{A}, \mathrm{O}$ \\
\hline $\begin{array}{l}\text { Change in } \\
\text { Interest* }\end{array}$ & $\begin{array}{ll}5 & \\
4 & \mathbf{5} \\
2 & \mathbf{b u} \\
1 & \end{array}$ & $\begin{array}{ll}5 & \\
4 & \\
3 & \mathbf{0} \\
1 & \\
1 & \end{array}$ & 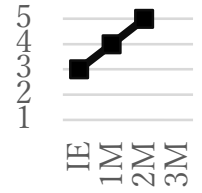 & $\begin{array}{ll}5 & \\
4 & \\
3 & \mathbf{a n} \\
2 & \mathbf{u} \\
1 & \end{array}$ & 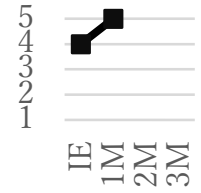 & $\begin{array}{ll}5 & \boldsymbol{D} \\
4 & \mathbf{0} \\
3 & \\
1 & \\
1 & \end{array}$ & $\boldsymbol{P}^{\boldsymbol{m}}$ \\
\hline
\end{tabular}
(objects) = displaying attachment to or relating to inanimate objects.

${ }^{2}$ Change in interest: $5=$ requests for and touch PARO voluntarily, $4=$ touch PARO voluntarily if it is presented, $3=$ interact with PARO if encouraged by others, $2=$ hardly interacts with PARO even if encouraged, $1=$ completely ignore and rejects PARO. 
322 The caregivers reported that subjects displayed a positive reaction to PARO (14 labels)

323 in the first month. However, this positive reaction was less noted in subsequent interviews

324 at the second (4 labels) and third (3 labels) months. Improvement in behaviours, which

325 include increased frequency of interaction and diminished agitations, were also reported

326 within the first (4 labels) and second (4 labels) months only. Additionally, the content of

327 reported behaviour considered as an 'improvement' was related to the volume or content

328 of conversations done amidst PARO. The trend observed can be because it was easier for

329 the families to recognise any changes of the subjects' behaviour and to think of ways to

330 encourage the use of PARO during the first month as compared to other months. This can

331 also mean that they have been enacting same patterns of encouragement in subsequent

332 months thus, no longer thought that it is still worthwhile to report it. Reports concerning

333 negative reactions, on the other hand, emerged from the second (4 labels) and third (3

334 labels) months. Quotations supporting the categories are shown in table 3.

336 The caregivers themselves also received direct and indirect benefits from interacting with

337 PARO. They got more time to interact with the subject, to do chores, and to simply feel

338 good and relaxed. A caregiver shared, "I was able to talk about fond memories with the

339 subject in PARO's presence." However, during the first month, the operation of PARO 
340 was a challenge. Five inquiries (from three families) were received concerning charging

341 PARO and locating the switch of PARO. These issues were resolved as familiarity with

342 PARO was established in the subsequent months. While the caregivers enjoyed the use

343 of PARO, several caregivers of subjects who did not achieve their goal voiced out the

344 inapplicability of PARO on the second and third months. One caregiver even blamed their

345 self as they said, "It was a shame that I wasn't able to encourage to use PARO very well".

346 Caregivers' experiences can be found in table 3. 


\begin{tabular}{|c|c|c|c|}
\hline \multicolumn{4}{|c|}{ Subject's Reaction to PARO } \\
\hline & Categories & Comments & Labels \\
\hline \multirow{2}{*}{ 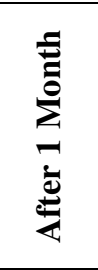 } & Positive reaction & $\begin{array}{l}\text { - "Talking PARO is like talking to a child" } \\
\text { - "She sat up and reached to pet PARO" }\end{array}$ & 14 \\
\hline & $\begin{array}{l}\text { Improved } \\
\text { behaviour }\end{array}$ & $\begin{array}{l}\text { - "She stopped wandering around and stayed seated" } \\
\text { - "She became more accepting of care aids" } \\
\text { assistance" }\end{array}$ & 4 \\
\hline \multirow{3}{*}{ 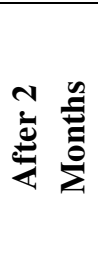 } & Positive reaction & $\begin{array}{l}\text { - "She appears to love PARO very much" } \\
\text { - "She often asks for PARO's whereabouts" }\end{array}$ & 4 \\
\hline & $\begin{array}{l}\text { Improved } \\
\text { behaviour }\end{array}$ & $\begin{array}{l}\text { - "She talked more frequently. The conversation } \\
\text { became gentler" }\end{array}$ & 4 \\
\hline & Negative reaction & - "She said I should play with PARO instead" & 1 \\
\hline \multirow{2}{*}{ 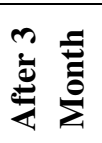 } & Positive reaction & - "She is always petting PARO" & 3 \\
\hline & Negative reaction & - "Appears to not like PARO" & 3 \\
\hline
\end{tabular}

Family's experience with PARO

\begin{tabular}{|c|c|c|c|}
\hline & Categories & Comments & Labels \\
\hline \multirow{5}{*}{$\frac{D}{\sum_{\bar{E}}^{0}}$} & Felt soothed & $\begin{array}{l}\text { - } \quad \text { PARO was so cute } \\
\text { - } \quad \text { PARO is good enough to call it a pet }\end{array}$ & 4 \\
\hline & $\begin{array}{l}\text { Increased interaction with } \\
\text { subject }\end{array}$ & $\begin{array}{l}\text { - } \quad \text { We talked about our old pet } \\
\text { - } \quad \text { We played a trivia game about seals }\end{array}$ & 1 \\
\hline & Maintenance and Function & $\begin{array}{l}\text { - } \quad \text { PARO doesn't charge sometimes } \\
\text { - } \quad \text { PARO was heavier than I thought }\end{array}$ & 2 \\
\hline & Benefits for caregiver & - $\quad$ PARO gave me time to complete chores & 1 \\
\hline & Reduced feeling of guilt & $\begin{array}{l}\text { - I can leave the subject without feeling like } \\
\text { neglecting her }\end{array}$ & 1 \\
\hline \multirow{5}{*}{ 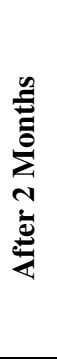 } & Felt soothed & - $\quad$ I like PARO more than the subject & 4 \\
\hline & $\begin{array}{l}\text { Increased interaction with } \\
\text { subject }\end{array}$ & - Reminded me of how my mother used to be & 1 \\
\hline & Benefits for caregiver & - I felt like I was being useful & 2 \\
\hline & Reduced feeling of guilt & $\begin{array}{l}\text { - The amount of care remains the same, but my } \\
\text { feeling of guilt is less }\end{array}$ & 1 \\
\hline & Not applicable for use & - The subject just isn't interested in PARO & 1 \\
\hline \multirow{3}{*}{ 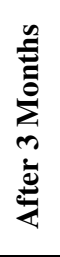 } & Felt soothed & $\begin{array}{l}\text { - I felt soothed by PARO. It may also have a } \\
\text { positive effect on the subject }\end{array}$ & 2 \\
\hline & Benefits for caregiver & - I felt like I was useful to the subject & 1 \\
\hline & Not applicable for use & $\begin{array}{l}\text { - The subject did not use PARO. Maybe I did not } \\
\text { facilitate it correctly }\end{array}$ & 1 \\
\hline
\end{tabular}




\section{Effectiveness of PARO Activities:}

351 Five subjects reacted positively to PARO and achieved their set intervention goals. Based on the characteristics of the positive results, it is possible to infer that activities using PARO could expand the potential of people who are interested in PARO. research findings regarding the use of PARO revealed that it is effective in (1) increasing spontaneous activity, (2) reducing uneasiness/restlessness, (3) respiting from the burden of supervision for family caregivers, (4) feeling soothed, and (5) feeling uplifted. Furthermore, previous research in topics related to the use of PARO resulted in experiencing a desirable difference in terms of agitation, mood, emotion (joyfulness, loneliness), stress, anxiety, physical activation, facial expression, and communication [817].

364 Moreover, PARO exhibits the potential to spark activities that meet the needs enumerated by the PCC philosophy [30]. The effect of utilising PARO in this research positively impacted the subjects' conditions. PARO is expected to decrease care burden and enable 
367 improved dealings with the subjects. Activities with PARO facilitate the subjects' feeling

368 of ease (comfort), and the subjects in a calm state of mind reminiscing about their past

369 life events (identity), which then increases communication with families and offers

370 occasions to feel connected as a family member (attachment and inclusion). In cases

371 where subjects were conscious of taking care of PARO, the need for 'occupation' was

372 fulfilled. Meeting the five needs as identified in the PCC approach is said to improve the

373 well-being of people with dementia [30]. We identified that effective use of PARO at

374 home can be valid as a tool for care provision.

$376 \quad$ Factors identified for PARO use:

377 From an environmental perspective, the use of PARO increased time spent being active,

378 thereby obtaining healing and fun, creating a constructive cycle of wanting to interact

379 again with PARO. However, PARO may not be appropriate for individuals who do not

380 exhibit any sign of interest. Since these responses were observed from the time of the first

381 introduction or during the first month, it suggests the possibility of being able to predict

382 the appropriateness of using PARO at the time of the first meeting. It is not reasonable to

383 expect a positive result from PARO use with a family caregiver when PARO is rejected

384 from the onset. 
385 However, for subjects who only interacted with PARO when encouraged (scored 3) at the

386 initial visit, level of interest may increase (cases 3 and 7) or decrease (cases 1 and 4).

387 Hence, there should be a month trial period to confirm the subject's level of interest as

388 the potential for effective PARO use became apparent after 2 months of use. Furthermore,

389 when the subject's interest in PARO diminished soon after the initial encounter, extending

390 the duration of using PARO did not improve the level of interest. Nevertheless, providing

391 sufficient support and advice at the initial stage by a HCP may lead to more appropriate

392 and continued use of PARO.

393

394 Figure 3 illustrates the applicability of utilising PARO as indicated by the level of subjects'

395 reaction to PARO. Hypothesis obtained from this study should be considered from a long-

396 term efficacy perspective.

397 


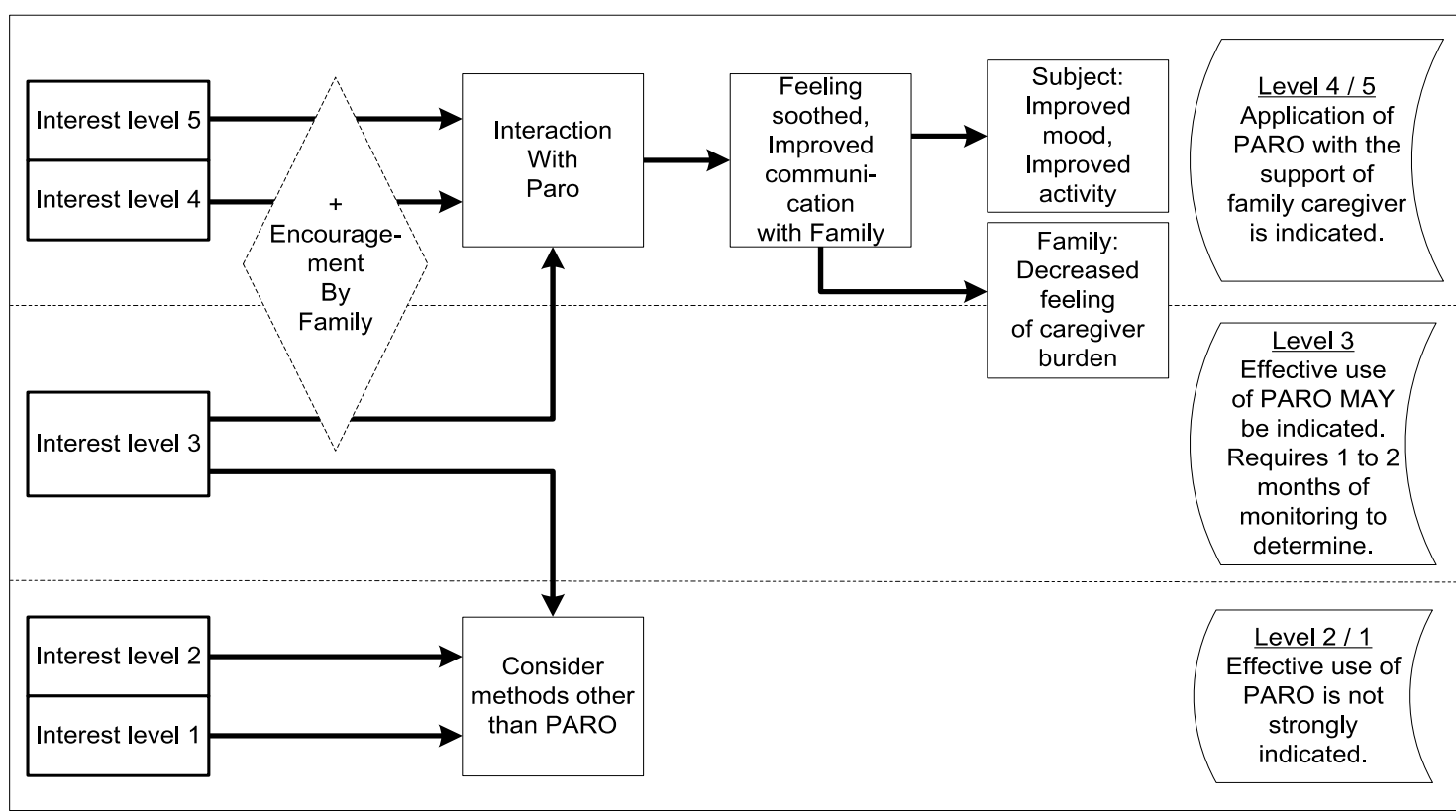

Figure 3 Application of PARO use indicated by the level of the subject's interest

Supports Considered Necessary to Use PARO in a Home Care Setting:

During this research, we provided families with instructions and advice regarding 'A - 
410 and advise related to 'G' and 'I' should be given during the initial meeting in addition to

411 'A' and ' $\mathrm{O}$ ', as it might help widen the scope of care by the family. By receiving

412 instructions from $\mathrm{HCP}$ at the time of the introduction of PARO, it is expected that the

413 family can expand both the variety and extent of the subjects' activities.

415 Two reports found that family caregivers of EPWD use everyday technology such as

416 smartphones to support care provision $[18,19]$. Robot technology is currently used for

417 home alliances, with an expectation to expand into the field of dementia care. Given this,

418 the HCP could support successful participation in the activity by discussing proper

419 handling procedures to the family, setting-up PARO in a manner tailored to the subject,

420 educating means to encourage the subject to use PARO, and clarifying the benefits of the

421 activity. This research finding responds to the challenge posed by Hung that "Future

422 research should pay more attention to the clinical needs of the patient population and

423 develop strategies to overcome barriers to the adoption of PARO in order to maximise

424 patient benefits." $[9$, p. 1]

426 The general assumption in using assistive technology under public funding in Japan is to

427 use it only when required and discontinue as soon as it becomes unnecessary. Similarly, 
428 PARO does not need to be used for a prolonged period and may be discontinued once the

429 purpose is achieved. Judging whether the purpose is achieved is thought to be difficult

430 for the layperson, so an evaluation by an HCP must be done before the termination of

431 PARO. HCPs, such as occupational therapists who provide individually-tailored

432 interventions, can generate better outcomes in dementia care $[32,33]$.

434 In summary, this investigation has shown that when PARO is used in-home care,

435 individuals who displayed an active interest in PARO from the beginning would

436 voluntarily increase the time spent with PARO, leading to a decrease in BPSD.

437 Furthermore, the above effects are augmented further when care is provided by a family

438 member, with the support of a HCP involved in dementia care. The fundamental response

439 to BPSD depends on matters like environmental adjustment, the caregiver's facial

440 expression, and the appropriateness of displayed behaviour. Results showed that when an

441 object such as PARO is introduced, the EPWD naturally becomes calm and proactively

442 makes time to spend with it. Hence, PARO can be considered an effective support tool

443 for family care. 
Limitations:

447 It should be noted that this report is a summary of a study of seven cases that were

448 recruited through a public notice, so the participating families had positive attitudes as

449 caregivers, and the result should be interpreted in consideration of it. Accordingly, the

450 benefits observed may not apply to all cases. In the future, it will be necessary to use a

451 larger number of subjects to investigate ways of providing more effective and practical

452 support. Additionally, it will be helpful to explore ways of combining home-based and

453 day-care facility services.

\section{CONCLUSION}

456 Five participants showed active interest and interaction from the first meeting. For these subjects, PARO was able to achieve its purpose. PARO may not be an ideal intervention for people who exhibit little interest at the time of introduction. This study found that the

459 characteristics of individuals who could potentially benefit from PARO are distinguished

460 not according to the severity of dementia but by one's level of interest in PARO

461 (recognising PARO as cute and being willing to touch it actively). In the context of family

462 care, PARO is expected to elicit an active engagement with itself leading to the reduction

463 of BPSD and burden on caregivers. Rather than just handing PARO over to families, 
464 HCPs, such as occupational therapists, should teach families how to use PARO

465 effectively, support the process of encouragement to use PARO, and support the decision

466 of when to terminate the use of PARO.

467

468 List of Abbreviations

469 MHLW: Ministry of Health, Labour and Welfare

470 EPWD: Elderly Persons with Dementia

471 HCP: HealthCare Professional

472 RCT: Randomised Controlled Trial

473 PCC: Person Centred Care

474 MMSE-J: Mini-Mental Status Examination-Japanese

475 N-ADL: Nishimura's Activity of Daily Living Scale

476 DBD: Dementia Behaviour Disturbance Scale

477 DCM: Dementia Care Mapping

478 BCC: Behaviour Category Code

479 BPSD: Behavioural and Psychiatric Symptoms of Dementia

480 PI: Principal Investigator 


\section{Declarations}

483

\section{Ethics approval and Consent to Participate}

This study was approved by the Tokyo Metropolitan University Ethics Review Board (approval number: HINO-159), who has authority over the author. The experiment protocol for involving humans was in accordance to the guidelines of Tokyo Metropolitan University and the Declaration of Helsinki. The research team provided verbal and written explanations and obtained consent from participants and families. In particular, it clearly communicated to the families, both verbally and written, that their privacy is protected, PARO does not have to be encouraged when participants are in poor health, and that even after consenting, participation can be stopped at any time if the subject indicates refusal.

\section{$\underline{\text { Consent for Publication }}$}

Not Applicable

\section{$\underline{\text { Availability of data and materials }}$}

The datasets generated and/or analysed during the current study are not publicly available to protect the participants' right to privacy and confidentiality but are available from the corresponding author on reasonable request. 


\section{$501 \quad$ Competing interest}

502 TS who invented PARO was not involved in tasks directly influencing the clinical data

503 collection and analysis. All other authors declare no conflict of interest

Funding

506 This study was conducted with a 2012-2016, 2019-2021 fiscal years Basic Scientific

(B) [grant IDs: 24300202; 19H04504]. The funding parties had no influence on the conduct of this research.

$511 \quad$ Author's' contributions

$512 \mathrm{KI}, \mathrm{KW}, \mathrm{CS}$, and TS were involved in establishing the research design. With the

513 assistance of CS, KI facilitated recruitment of the subjects and data collection. KI

514 synthesised collected data in discussion with the research team and drafted this article.

515 CS, CY, and DPGY reviewed and revised the content of this article. All authors read and

516 gave permission for this version to be submitted for publication. All authors are

517 accountable for all aspects of this work. 


\section{$518 \quad$ Acknowledgments}

519 We would like to thank everyone who cooperated in this research.

520 This study was conducted with the 2012-2016, 2019-2021 fiscal years Basic Scientific

521 Research grant from the Ministry of Education, Culture, Sports, Science, and Technology

522 (B) [grant IDs: 24300202; 19H04504]

523

524

525

526

527

528

529

530

531

532

533

534

535

Page 35 of 41 


\section{References}

537 1. Ministry of Health, Labor and Welfare. Establishing 'the community-based

538 integrated care system'. https://www.mhlw.go.jp/english/policy/care-welfare/care-

$539 \quad$ welfare-elderly/dl/establish_e.pdf. Accessed 10 July 2020.

2. Chiao C-Y, Wu H-S, Hsiao C-Y. Caregiver burden for informal caregivers of patient with dementia: A systematic review. Int Nurs Rev. 2015;62(3):340-50. doi:10.1111/inr.12194

3. Ministry of Health, Labor and Welfare. Heisei 28-nendo "koureishagyakutai no taiou joukyoutou ni kansuru chousa kekka [Japanese]. 2018. https://www.mhlw.go.jp/stf/houdou/0000196989.html. Accessed 10 April 2020

4. Global Note. Sekai no koureikaritsu (koureisha jinjou hiritsu) kunibetsu ranking suii (Japanese). 2020. https://www.globalnote.jp/post-3770.html. Accessed 15 April 2020

5. Ministry of Health, Labor and Welfare. 2025 nen ni muketa kaigoujinzai ni kakaru jukyuusuikei (kakuteichi) ni tsuite (Japanese). 2015. https://www.mhlw.go.jp/file/04-Houdouhappyou-12004000-Shakaiengokyoku- 
554

6. Robotto kakumei jitsugen kaigi. Robotto shinsenbyaku youyaku. 2015. http://www.kantei.go.jp/jp/singi/robot/pdf/senryaku_youyaku.pdf. Accessed 11 August 2020

7. Shibata T. Development and spread of therapeutic medical robot, PARO: Innovation of non-pharmacological therapy for dementia and mental health (Japanese). Journal of Information Processing and Management, 2017;60(4):217-28. doi:10.1241/johokanri.60.217

8. Kang HS, Makimoto K, Konno R, Koh IS. Review of outcome measures in PARO robot intervention studies for dementia care. Geriatr Nurs, 2020;41(3):207-14. doi:10.1016/j.gerinurse.2019.09.003

9. Hung L, Liu C, Woldum E, Au-Yeung A, Berndt A, Wallsworth C, et al. The benefits of and barriers to using a social robot PARO in care settings: A scoping review. BMC Geriatr. 2019;19(1):232. doi:10.1186/s12877-019-1244-6

10. Moyle W, Cooke M, Beattie E, Jones C, Klein B, Cook G, et al. Exploring the effect of companion robots on emotional expression in older adults with dementia: A pilot randomized controlled trial. J Gerontol Nurs. 2013;39(5):46-53. doi:10.3928/00989134-20130313-03

11. Moyle W, Jones CJ, Murfield JE, Thalib L, Beattie ERA, Shum DKH, et al. Use of 
a robotic seal as a therapeutic tool to improve dementia symptoms: A clusterrandomized controlled trial. J Am Med Dir Assoc. 2017;18:766-73. Doi:10.1016/j.jamda.2017.03.018 and depression in persons with dementia participating in robot-assisted activity: A cluster-randomized controlled trial. J Am Med Dir Assoc. 2015;16(10):867-73. doi:10.1016/j.jamda.2015.05.002

13. Liang A, Piroth I, Robinson H, MacDonald B, Fisher M, Nater UM, et al. A pilot randomized trial of a companion robot for people with dementia living in the community. J Am Med Dir Assoc. 2017;18(10):871-8.

14. Robinson H, MacDonald B, Kerse N, Broadbent E. The psychosocial effects of a companion robot: A randomized controlled trial. J Am Med Dir Assoc. 2013;14(9):661-7. doi:10.1016/j.jamda.2013.02.007

15. Petersen S, Houston S, Qin H, Tague C, Studley J. The utilization of robotic pets in dementia care. J Alzheimers Dis. 2017;55(2):569-74. doi:10.3233/JAD-160703 seal on the motor activity and sleep patterns of older people with dementia, as 
measured by wearable technology: A cluster-randomised controlled trial. Maturitas,

17. Jones C, Moyle W, Murfield J, Draper B, Shum D, Beattie E, et al. Does cognitive impairment and agitation in dementia influence intervention effectiveness? Findings from a cluster-randomized-controlled-trial with the therapeutic robot, PARO. J Am Med Dir Assoc. 2018;19(7):623-6. doi:10.1016/j.jamda.2018.02.014

18. Block L, Gilmore-Bykovskyi A, Jolliff A, Mullen S, Werner NE. Exploring dementia family caregivers' everyday use and appraisal of technological supports. Geriatr Nurs. in press. doi:10.1016/j.gerinurse.2020.06.019

19. Holthe T, Jentoft R, Arntzen C, Thorsen K. Benefits and burdens: Family caregivers' doi:10.1080/17483107.2017.1373151

20. Kitwood T. Dementia reconsidered: The person comes first. London: Open University Press; 1997

21. Shibata T, Wada K. Robot therapy: A new approach for mental healthcare of the elderly - A mini-review. Gerontology. 2011;57(4):378-86. doi:10.1159/000319015 

therapeutic robot Paro. http://paro.jp/?page_id=326. Accessed 15 March 2020

609

610

611

23. Folstein MF, Folstein SE, McHugh PR. "Mini-mental state". A practical method for grading the cognitive state of patients for the clinician. J Psychiatr Res. 1975;12(3):189-98. doi:10.1016/0022-3956(75)90026-6

24. Kobayashi T, Hariguchi S, Nishimura K, Takeda M, Hakunaga T. A new clinical scale for rating of mental states and activities of daily living of the elderly (NM scale and N-ADL) (Japanese). Jpn J Clin Psychiatry. 1988;17(11):1653-68.

25. Baumgarten M, Becker R, Gauthier S. Validity and reliability of the dementia behavior disturbance scale. J Am Geriatr Soc. 1990;38(3):221-6. doi:10.1111/j.15325415.1990.tb03495.x

26. Zarit SH, Zarit JM. The memory and behavior problems checklist and the burden interview. University Park, PA: Pennsylvania State University, Gerontology Center; 1990.

27. Sugishita M, Hemmi I, Takeuchi T. Reexamination of the Validity and Reliability of the Japanese Version of the Mini-Mental State Examination (MMSE-J) (Japanese). Jpn J Cogn Neurosci. 2016;18(3):168-83. doi:10.11253/ninchishinkeikagaku.18.168

28. Mizoguchi T, Iijima S, Eto F, Ishizuka A, Orimo H. Reliability and validity of Japanese version of the dementia behavior disturbance scale (Japanese). Jpn J Geriatr. 

1993;30(10):835-40. doi:10.3143/geriatrics.30.835

627 29. Arai Y. Assessment of family caregiver burden in the context of the LTC insurance system (Japanese). Jpn J Geriatr. 2005;42(2):195-8. doi:10.3143/geriatrics.42.195

30. Brooker D, Surr C. Dementia care mapping: Principles and practice. Bradford: $630 \quad$ University of Bradford; 2005

31. Bradford Dementia Group. DCM 8 user's manual. Badford: University of Bradford; 2005

32. Vandepitte S, van den Noortgate N, Putman K, Verhaeghe S, Faes K, Annemans L. Effectiveness of supporting informal caregivers of people with dementia: A systematic review of randomized and non-randomized controlled trials. J Alzheimers Dis. 2016;52(3):929-65. doi:10.3233/JAD-151011

33. Marx K, Scott J, Pierson C, Griffin L. Tailored activities to reduce neuropsychiatric behaviors in persons with dementia: Case report. Am J Occup Ther. 2019;73(2):1-9. doi:10.5014/ajot.2019.029546 
Figures

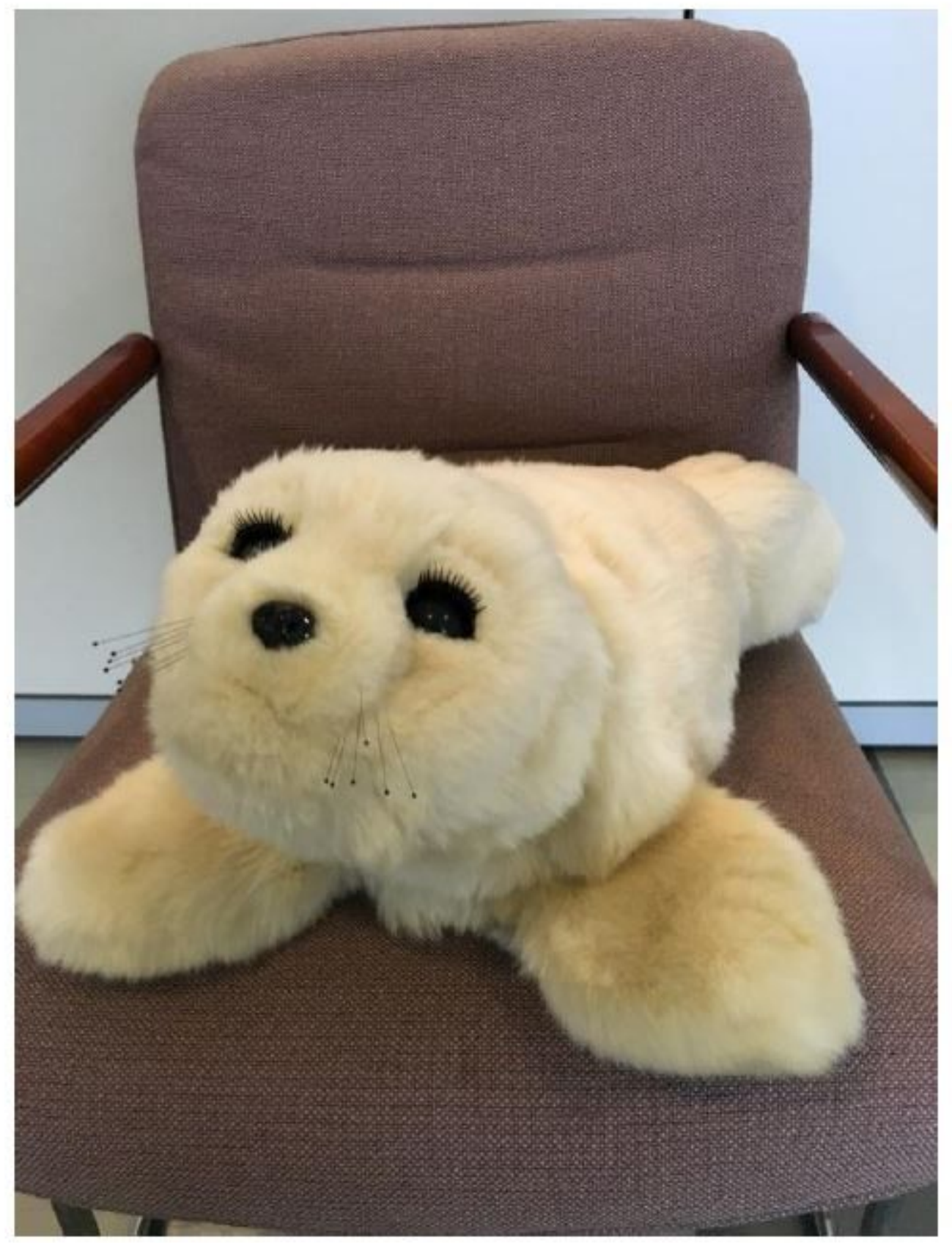

Figure 1

PARO 


\section{At Initial Visit \\ Intervention Phase \\ (and subsequent visits) \\ Termination}

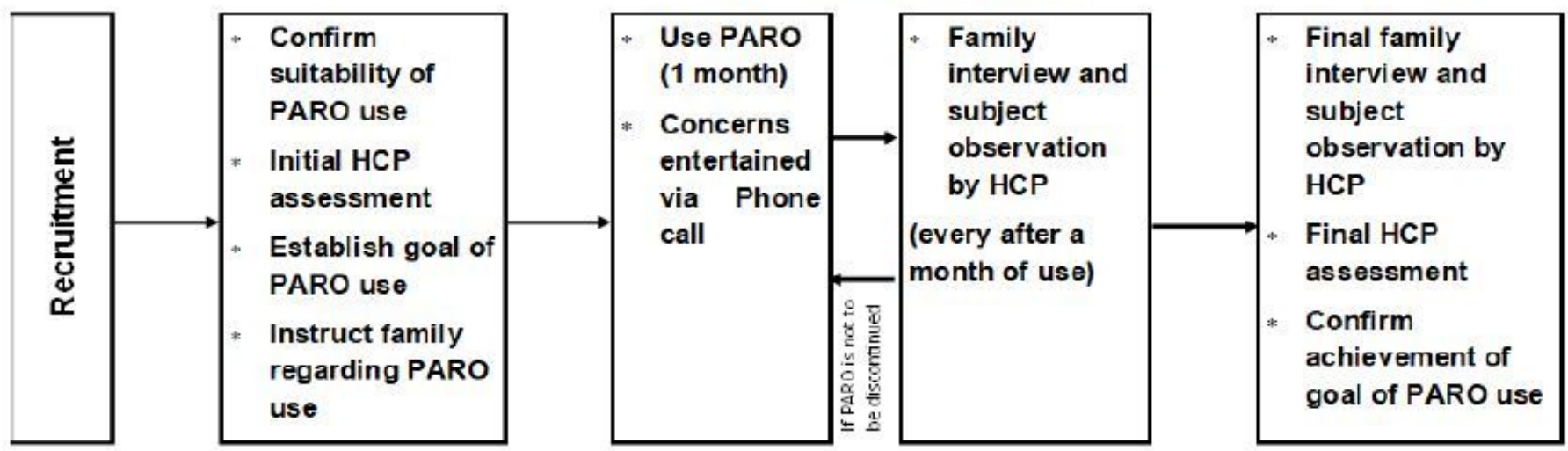

Figure 2

\section{Process of data collection}

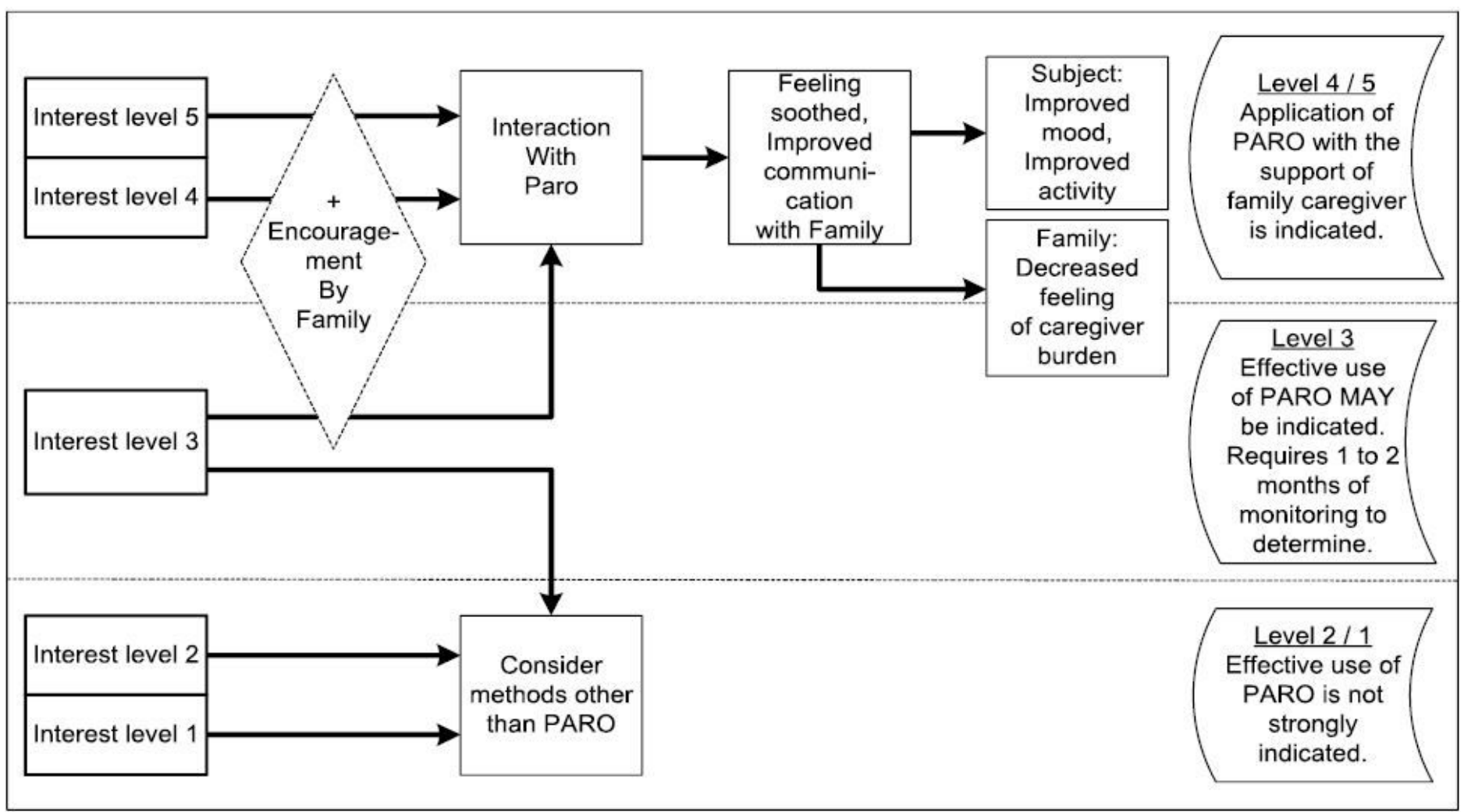

Figure 3

Application of PARO use indicated by the level of the subject's interest

\section{Supplementary Files}


This is a list of supplementary files associated with this preprint. Click to download.

- Suppl1.pdf 